\title{
Unusual Complication of Abdominal Pseudocyst Following Cystoperitoneal Shunt in Posterior Cranial Fossa Arrachnoid Cyst
}

\author{
Prastiya Indra Gunawan ${ }^{1}$, Rahadian Indarto Susilo ${ }^{2}$ \\ ${ }^{l}$ PhD Pediatric Neurology Lecturer, Department of Pediatrics, ${ }^{2}$ PhD Neurosurgery Lecturer, Department of \\ Neurosurgery, Faculty of Medicine, Universitas Airlangga, Dr Soetomo Hospital, Surabaya, Indonesia
}

\begin{abstract}
Abdominal pseudocyst is a rare complication reported of VP shunt surgery. Here, we report a 10-monthsold boy with abdominal distension following cystoperitoneal (CP) shunt procedure for the fossa posterior arrachnoid cyst. The diagnosis was based on the clinical symptoms and abdominal USG. Infection and allergic reaction was considered as the underlying cause. The CP shunt was removed to atrioventricular shunt and it resulted in a good response. Abdominal pseudocyst should be considered whenever there is abdominal distension following VP/CP shunt.
\end{abstract}

Keywords: abdominal pseudocyst, cystoperitonal shunt, atrioventricular shunt

\section{Introduction}

Posterior cranial fossa arrachnoid cyst is the presence of cysts or cavities within the brain that result from developmental defects or acquired lesions. Its account for $1 \%$ among all intracranial space-occupying lesions and 2,6\% among the population aged below 18 years ${ }^{1,2,3}$.

Abdominal complications are reported to occur in $5-7 \%$ cases following VP shunt operations. ${ }^{1}$ Abdominal CSF pseudocyst is a rare complication reported to occur in $<1 \%$ to $4.5 \%$ of VP shunt surgery ${ }^{3-5,6}$. Diagnosis of CSF pseudocyst can be confirmed by ultrasound examination of abdomen and pelvis. Ultrasonographic evidence of a large localized, or loculated collection of peritoneal CSF is abnormal and suggests CSF pseudocyst ${ }^{3,4,7}$.

Traditional staged treatment consists of exploratory laparotomy, removal of shunt or shunt externalization, with or without cyst excision and placement of shunt catheter in different quadrant or conversion of VP shunt to VA shunt ${ }^{8-10}$.
The purpose of this case report was to describe an unusual complication of abdominal pseudocyst following 3 weeks cystoperitoneal shunt in posterior cranial fossa arrachnoid cyst.

\section{The Case}

A 10-months-old boy admitted to Dr. Soetomo Hospital Surabaya with the chief complaint of abdominal distension. It was observed for one weeks following cystoperitoneal (CP) shunt for the fossa posterior cyst three weeks before admission. The patient was irritable and having recurrent vomiting as well as the prolong fever. He was presenting with macrocephaly, sunset phenomenon sign and bulging fontanels. The neurologic examination revealed positive for Babinski reflexes on both legs.

The cerebrospinal fluid analysis revealed yellowish, pleocytosis in which $66 \%$ were polimorphonuclear, glucose level $56 \mathrm{mg} / \mathrm{dL}$, and total protein $281.4 \mathrm{mg} /$ dL. Serology examination showed positive for $\mathrm{IgG}$ CMV and eosinophila count was $5 \times 10^{9} / \mathrm{L}$. The Head 
MRI showed that there were cranial posterior fossa arrachnoid cyst with tip of shunt in the location of cyst (Figure 1). Abdominal ultrasonography showed cyst in abdominal region $9.89 \times 8.01 \mathrm{~cm}$ in a thin layer (Figure 2). The patient treated with ceftriaxone twice daily $500 \mathrm{mg}$ intravenously and removal of CP shunt.

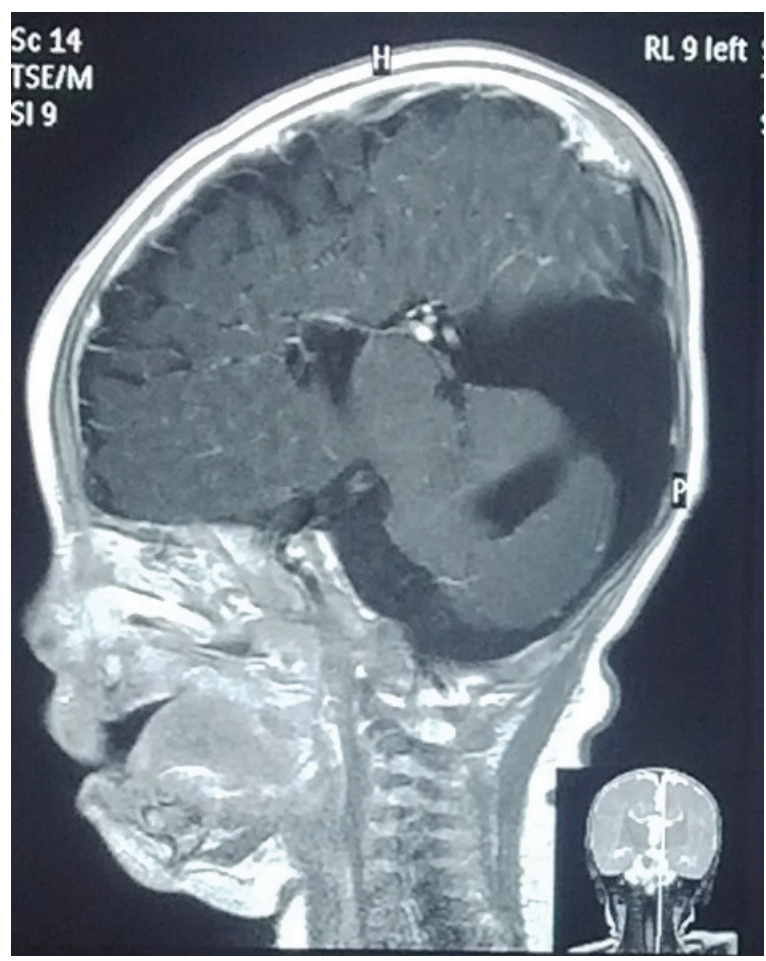

Figure 1. Head MRI showing for cranial posterior fossa cyst from sagital view.

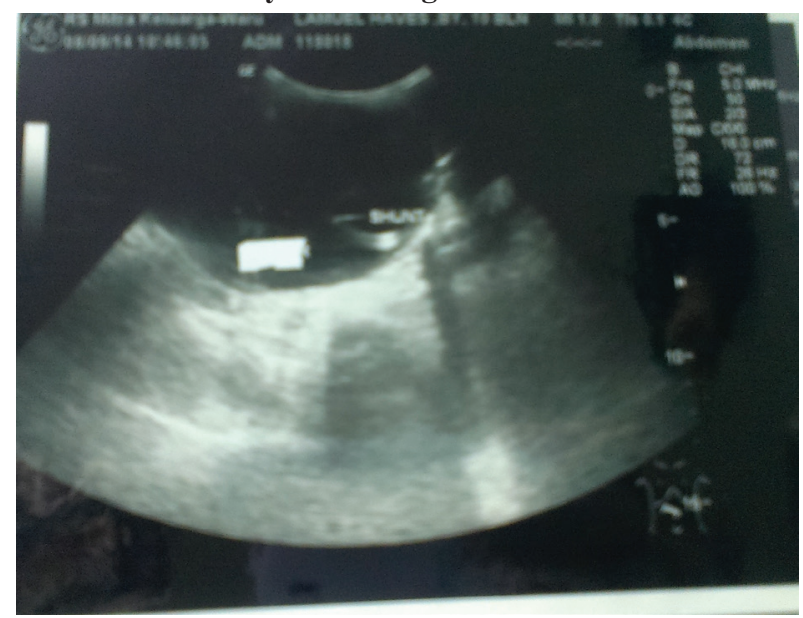

Figure 2. Abdominal USG showed cyst in abdominal region with diameter size $9.89 \times 8.01 \mathrm{~cm}$ from distal of $\mathrm{CP}$ tip.

Neurosurgery performed laparotomy exploration to remove the cyst and converted the $\mathrm{CP}$ shunt to CystoAtrial (CA) shunt. Part of psudocyst was underwent histopathologic processing. It resulted a pseudocyst with chronic inflammation consisting fibrotic area with predominantly mononuclear and seldom of polimorfonuclear. After the surgery and medication given, the abdominal distension was reduced. The patient was then discharged in a good condition.

\section{Discussion}

The patient underwent $\mathrm{CP}$ shunt procedures for management of posterior cranial fossa arachnoid cyst. According to management of cerebral system shunt, this patient underwent $\mathrm{CP}$ shunt with CSF is shunted from cyst to the peritoneal cavity.

There are many types of complication folowing VP or CP shunt ${ }^{11,12}$. The abdominal distension following $\mathrm{CP}$ shunt of posterior cranial fossa cyst occurred within 3 weeks. Abdominal pseudocysts tend to occur within 6 month of the last intraabdominal surgical intervention ${ }^{8,9}$. The abdominal CSF pseudocyst can occur any time between several weeks and several years after the final procedure of the V-P shunt ${ }^{10}$. Abdominal CSF pseudocyst is well known as a rare complication of the V-P shunt. The reported incidence varies from $0.7 \%$, $3.2 \%$ and $4.5 \%$ from several study ${ }^{5,7}$. Peritoneal CSF pseudocysts may present with (a) abdominal complaints, (b) symptoms of shunt malfunction, and (c) clinical manifestations of infection.

The etiology of pseudocyst in this case may be caused by infection or allergic reaction. The infection was considered from the clinical symptoms and the result of liquor cerebrospinal analysis and pseudocyst histopathologic findings, otherwise allergic reaction was analyzed from the eosinophil count. The presence of foreign bodies inside the peritoneal cavity activates macrophages (first defense line) and monocytes, which stimulate mesothelial cells to produce immunomediators. Initially, macrophages and monocytes are activated, which results in primary immunomediation of the inflammatory reaction ${ }^{5,10}$. Histologically, it is almost universally agreed that an inflammatory process has an important role in cerebrospinal fluid abdominal pseudocyst formation ${ }^{5,10}$. Previous study found that allergic reactions are another potential cause of the 
sterile inflammation leading to pseudocyst formation ${ }^{2}$. The eosinophilia and the increase in the serum IgE level can be indicated some allergic reaction. Furthermore, the infiltration of the eosinophils, which was identified in the specimens not only of the pseudocyst wall but also of the granular tissue around the CSF valve, suggested an aseptic inflammation against the silicone of the shunt material ${ }^{10}$.

Excision of abdominal pseudocyst and conversion of $\mathrm{CP}$ shunt to CA shunt were applied to the patient. An abdominal CSF pseudocyst may spontaneously disappear if the shunt catheter is simply removed and external ventricular drainage is required when the shunt infection is the etiology of the pseudocyst formation ${ }^{2,5}$. A V-P shunt can be replaced after the infection is driven out and the pseudocyst is resolved. The V-P shunt can be converted to a ventriculo-atrial shunt in some cases $^{5}$. Atrial shunt is used only as a last option, when the abdomen is unable to reabsorb cerebrospinal fluid avoiding the recurrence of abdominal pseudocyst ${ }^{8}$.

Prognosis of this patient was good after re insersion from CP shunt to CA shunt. The prognosis of abdominal pseudocyst after CP shunt were not constant, declining with time following a revision, and many factors influence on the prognosis, such as interval CSF revision and previous infection.

\section{Summary}

Cerebrospinal fluid abdominal pseudocyst is a rare complication of ventriculoperitoneal shunt but it is difficult to treat effectively. Shunt revisions and etiology seemed to be involved in cerebrospinal fluid abdominal pseudocyst. The patient had underwent revision of cystoperitoneal shunt to cystoatrial shunt. The procedure resulted in a good response.

Conflict of Interest: The authors expressly declare there is no conflict of interest

Ethical Clearance: This is a case report and inform consent was approved and taken from the parents.

Source of Funding: Self Funding

\section{References}

1. Huang JH, Mei WZ, Chen Y, Chen JW, Lin ZX. Analysis on clinical characteristics of intracranial arachnoid cyst in 488 pediatric cases. Int J Clin Exp Med 2015;8(10):18343-50.

2. Carlos B, Carlos F, Mario Chavez, Villarroel, Jose L. Ferrufino, Orlandi. Abdominal cerebrospinal fluid pseudocyst: a comparative analysis between children and adults. Childs Nerv Syst 2014;30:57980.

3. Sharma AK, Pandey AK, Diyora BD, Mamidanna $\mathrm{R}$, Sayal PP. Abdominal CSF pseudocyst in a patient with ventriculo-peritoneal shunt. Indian $\mathrm{J}$ Surg 2004;66:360-3.

4. Coley BD, Shiels WE 2nd, Elton S, Murakami JW, Hogan MJ. Sonographically guided aspiration of cerebrospinal fluid pseudocysts in children and adolescents.Am J Roentgenol 2004;183:1507-10.

5. Ricardo Santos, Aline Barbosa, Yvone Avalloni, Moraes Villel, Hélio Rubens Machado. An alternative approach for management of abdominal cerebrospinal fluid pseudocysts in children. Childs Nerv Syst 2007; 23:85-90.

6. Vinchon M, Dhellemmes P. Cerebrospinal fluid shunt infection: risk factors and long-term followup. Childs NervSyst 2006;22:692-7.

7. Belem H, Carelli F, Borges A, Pereira. Nonfunctional abdominal complications of the distal catheter on the treatment of hydrocephalus: an inflammatory hypothesis?Experience with six cases. Childs Nerv Sys 2006; 22: 1225-30.

8. Browd SR, Ragel BT, Gottfried ON, Kestle JR. Failure of cerebrospinal fluid shunts: part I: obstruction and mechanical failure. J Pediatr Neurol 2006;34:83-92.

9. Ricardo Santos, Aline Barbosa, Yvone Avalloni, Moraes Villel, Hélio Rubens Machado. An alternative approach for management of abdominal cerebrospinal fluid pseudocysts in children. Childs Nerv Syst 2007;23:85-90 
10. Hashimoto M, Yokota A, Urasaki, Tsujigami, Shimono M. A case of abdominal CSF pseudocyst associated with silicone allergy. Childs Nerv Syst 2004 20:761-64.
11. Gunawan PI, Ranuh IGMR, Atthiyah AF. Anal extrusion of the ventriculoperitoneal shunt catheter. AMA 2017;46(1):65-66.

12. Gunawan PI, Wardana URK. Ventriculoperitoneal shunt fracture in a child. PAMJ 2021;38(202). 